\title{
Laryngopharyngeal Reflux: Diagnosis, Treatment, and Latest Research
}

\author{
Andrea Maria Campagnolo ${ }^{1}$ Jaqueline Priston ${ }^{2}$ Rebecca Heidrich Thoen ${ }^{1}$ Tatiana Medeiros ${ }^{2}$ \\ Aída Regina Assunção ${ }^{1}$ \\ ${ }^{1}$ Department of Otolaryngology, Hospital Universitário Pedro Ernesto \\ (HUPE), Universidade do Estado do Rio de Janeiro (UERJ), Rio de \\ Janeiro/RJ, Brazil \\ 2 Department of Speech-Language Pathology (SLP), Universidade do \\ Estado do Rio de Janeiro (UERJ), Rio de Janeiro/RJ, Brazil \\ Address for correspondence Andrea Maria Campagnolo, MD, PhD, \\ Rua Visconde de Pirajá, 452/207, Ipanema, Rio de Janeiro/RJ, CEP \\ 22410-002, Brazil (e-mail: amcampag@ig.com.br). \\ Int Arch Otorhinolaryngol 2014;18:184-191.
}

\begin{abstract}
Introduction Laryngopharyngeal reflux (LPR) is a highly prevalent disease and commonly encountered in the otolaryngologist's office.

Objective To review the literature on the diagnosis and treatment of LPR.

Data Synthesis LPR is associated with symptoms of laryngeal irritation such as throat clearing, coughing, and hoarseness. The main diagnostic methods currently used are laryngoscopy and $\mathrm{pH}$ monitoring. The most common laryngoscopic signs are redness and swelling of the throat. However, these findings are not specific of LPR and may be related to other causes or can even be found in healthy individuals. Furthermore, the role of $\mathrm{pH}$ monitoring in the diagnosis of LPR is controversial. A therapeutic trial with

Keywords

- laryngopharyngeal reflux

- laryngoscopy

- esophageal pH monitoring

- proton pump inhibitors

- biomarkers

- pharmacologic proton pump inhibitors (PPIs) has been suggested to be cost-effective and useful for the diagnosis of LPR. However, the recommendations of PPI therapy for patients with a suspicion of LPR are based on the results of uncontrolled studies, and high placebo response rates suggest a much more complex and multifactorial pathophysiology of LPR than simple acid reflux. Molecular studies have tried to identify biomarkers of reflux such as interleukins, carbonic anhydrase, E-cadherin, and mucin.

Conclusion Laryngoscopy and $\mathrm{pH}$ monitoring have failed as reliable tests for the diagnosis of LPR. Empirical therapy with PPIs is widely accepted as a diagnostic test and for the treatment of LPR. However, further research is needed to develop a definitive diagnostic test for LPR.
\end{abstract}

\section{Introduction}

Laryngopharyngeal reflux (LPR) is defined as the retrograde flow of stomach content to the larynx and pharynx whereby this material comes in contact with the upper aerodigestive tract. ${ }^{1}$ In contrast, gastroesophageal reflux disease (GERD) is the flow of stomach acids back into the esophagus. Acid reflux diseases are highly prevalent and GERD and LPR are epidemic. ${ }^{2-6}$ According to El-Serag, ${ }^{2}$ the prevalence of reflux diseases (GERD and LPR) has increased by $4 \%$ every year since 1976, and data from the National Cancer Institute of the United States show an increase in the prevalence of esophageal cancer of $600 \%$ since $1975 .{ }^{5}$ Altman et al reported a $500 \%$ increase in visits to the otolaryngologist due to LPR between 1990 and 2001. ${ }^{3}$ Moreover, it is estimated that LPR is present in more than $50 \%$ of patients with dysphonia. ${ }^{7}$

LPR has been implicated in the etiology of many laryngeal diseases such as reflux laryngitis, subglottic stenosis, received

December 14, 2012

accepted

June 6, 2013
DOI http://dx.doi.org/

10.1055/s-0033-1352504. ISSN $1809-9777$.
Copyright $\odot 2014$ by Thieme Publicações License terms Ltda, Rio de Janeiro, Brazil 
laryngeal carcinoma, granulomas, contact ulcers, and vocal nodules. ${ }^{8,9}$ Patients with LPR may endure prolonged and exhaustive suffering if the physician is unable to establish a diagnosis because the signs and symptoms of the disease are nonspecific and can be manifestations of other etiologies, such as infection, vocal abuse, allergy, smoking, irritant inhalation, heavy drinking, or nonpathologic alterations. However, when presented together, the signs and symptoms are a strong indicator of reflux. ${ }^{1}$

\section{Literature Review}

\section{Harmful Events}

\section{Physiological Barriers}

The physiological barriers to LPR include the lower esophageal sphincter, esophageal clearance influenced by esophageal peristalsis, saliva and gravity, and the upper esophageal sphincter. When these barriers fail, stomach content comes in contact with the laryngopharyngeal tissue, causing damage to the epithelium, ciliary dysfunction, inflammation, and altered sensitivity. It is believed that carbonic anhydrase type III exerts an important protective function in the epithelium of the larynx through the active secretion of bicarbonate, regulating $\mathrm{pH}$ in response to acid reflux. Supporting this hypothesis, this enzyme was found to be absent in $64 \%$ of laryngeal tissue biopsies from patients with LPR. ${ }^{1}$

\section{Acid}

The $\mathrm{pH}$ of the pharynx is neutral ( $\mathrm{pH} 7)$, whereas stomach acids range in $\mathrm{pH}$ from 1.5 to 2 . Damage to the pharynx is the result of a decline in $\mathrm{pH}$ and exposure to reflux components such as pepsin, bile salts, and pancreatic enzymes. ${ }^{10}$ In the esophagus, 50 reflux episodes per day are considered to be normal, whereas in the larynx three episodes can already cause damage. ${ }^{11}$ However, the effect of acids on the larynx is unclear and some studies suggest that the combination of acid and pepsin is necessary to cause laryngeal injury. $^{12}$

\section{Pepsin}

Nonacid reflux has been associated with inflammation in both LPR and GERD. Impedance $\mathrm{pH}$ monitoring detected episodes of nonacid or weakly acid gastric reflux in symptomatic patients, ${ }^{13}$ suggesting that reflux components such as pepsin and bile salts can cause mucosal damage. Evidence indicates that pepsin is actively transported into laryngeal epithelial cells and remains stable at $\mathrm{pH} 7.4,{ }^{14}$ but is irreversibly inactivated at $\mathrm{pH}$. After pepsin is reactivated by a decline from $\mathrm{pH} 7.4$ to $\mathrm{pH} 3,72 \%$ of peptic activity remains. ${ }^{14}$ The activity of pepsin is optimal at $\mathrm{pH} 2 .^{10}$ Recent studies suggest that pepsin is the causative agent of laryngeal injury in nonacid reflux. ${ }^{11,13}$ At an average $\mathrm{pH}$ of 6.8, the larynx may contain stable pepsin that can be reactivated during subsequent reflux episodes or by hydrogen ions from any source, including dietary sources. ${ }^{4,10}$ Furthermore, there is evidence showing that pepsin can cause intracellular damage because cell components such as the Golgi complex and lysosomes have a low $\mathrm{pH}$ (5.0 and 4.0, respectively). ${ }^{14}$ In the study of Johnston et al, ${ }^{11}$ intracellular pepsin was detected by Western blot analysis of laryngeal biopsies in 19 of 20 patients with LPR documented by $\mathrm{pH}$ monitoring, but in only 1 of 20 controls. The presence of pepsin in tissue is associated with the depletion of key protective proteins such as carbonic anhydrase, E-cadherin, and Sep 70 (an epithelial stress protein). ${ }^{11,15} \mathrm{~A}$ recent study demonstrated that pepsin increases the levels of genetic markers associated with cancer. $^{16}$

\section{Bile Acids}

The reflux of duodenal-gastric juices contains bile acids and pancreatic secretions and can reach the larynx. ${ }^{17}$ The conjugated bile causes damage to the mucosa at low pH (1.2 to 1.5). ${ }^{18}$ The bile acid chenodeoxycholic acid is activated at $\mathrm{pH} 7$ and not at $\mathrm{pH} 2$. An experimental study showed that conjugated bile acids are more damaging to the mucosa at acid $\mathrm{pH}$, whereas chenodeoxycholic acid is active at $\mathrm{pH} 5$ to $8 .{ }^{17}$ In that study, the laryngeal mucosa of rats was exposed to taurocholic and chenodeoxycholic acid at $\mathrm{pH} 1.5$ to 7.4 and the results were compared with control rats exposed to saline. Taurocholic acid was more damaging to the mucosa at $\mathrm{pH} 1.5$, whereas chenodeoxycholic acid caused maximum inflammation at $\mathrm{pH}$ 7.4. The study suggested that bile can cause laryngeal inflammation at both acid and nonacid $\mathrm{pH}$. However, there is no evidence that the same mechanism occurs in the human larynx.

\section{Symptoms}

According to Koufman, ${ }^{8}$ it is important to recognize LPR and GERD as distinct entities. In Kaufman's study including 899 patients, throat clearing was observed in $87 \%$ of patients with LPR versus $3 \%$ of patients with GERD. On the other hand, only $20 \%$ of the patients with LPR reported heartburn or a burning sensation compared with $83 \%$ in the group with GERD.

The most common symptoms of LPR are excessive throat clearing, coughing, hoarseness, and globus pharyngeus ("lump in the throat sensation"). ${ }^{1}$ Hoarseness is generally a fluctuating symptom that occurs in the morning and improves during the day. ${ }^{19}$ Belafsky et al developed a nine-item questionnaire (Reflux Symptom Index [RSI]) for the assessment of symptoms in patients with reflux disease that can be completed in less than 1 minute. ${ }^{9}$ The scale for each individual item ranges from 0 (no problem) to 5 (severe problem), with a maximum score of 45 (-Table 1 ). The authors concluded that the questionnaire shows high reproducibility and validity for the diagnosis of reflux if an RSI score $>13$ is defined as abnormal. The RSI value was significantly higher in untreated LPR patients than in controls $(p<0.001)$. The authors concluded that the questionnaire shows high reproducibility and validity because the accuracy in documenting symptom improvement of patients with LPR. One challenge in diagnosing LPR is that the symptoms of the LPR disease lack sufficient specificity to confirm LPR and thus to rule out other causative agents. In fact, several studies have shown a poor correlation 
Table 1 Reflux Symptom Index

\begin{tabular}{|c|c|c|c|c|c|c|}
\hline $\begin{array}{l}\text { How did the problems listed below affect you since the last month? } \\
\text { Please circle the appropriate answer }\end{array}$ & \multicolumn{6}{|c|}{$\begin{array}{l}0=\text { no problem } \\
5=\text { severe problem }\end{array}$} \\
\hline 1. Hoarseness or voice problems & 0 & 1 & 2 & 3 & 4 & 5 \\
\hline 2. Throat clearing & 0 & 1 & 2 & 3 & 4 & 5 \\
\hline 3. Excess mucus or postnasal drip (descends behind the nose to the throat) & 0 & 1 & 2 & 3 & 4 & 5 \\
\hline 4. Difficulty in swallowing solids, fluids or tablets & 0 & 1 & 2 & 3 & 4 & 5 \\
\hline 5. Coughing after eating or lying down & 0 & 1 & 2 & 3 & 4 & 5 \\
\hline 6. Breathing difficulties or choking episodes & 0 & 1 & 2 & 3 & 4 & 5 \\
\hline 7. Annoying cough & 0 & 1 & 2 & 3 & 4 & 5 \\
\hline 8. Sensation of a lump or foreign body in the throat & 0 & 1 & 2 & 3 & 4 & 5 \\
\hline \multirow[t]{2}{*}{ 9. Burning, heartburn, chest pain, indigestion, or stomach acid coming up (reflux) } & 0 & 1 & 2 & 3 & 4 & 5 \\
\hline & \multicolumn{5}{|c|}{ Total } & \\
\hline
\end{tabular}

between LPR symptoms, laryngeal findings, and findings from hypopharyngeal $\mathrm{pH}$ registrations. ${ }^{20,21}$

\section{Diagnostic Methods}

\section{Laryngoscopy}

The laryngoscopic findings used for the diagnosis of reflux are nonspecific signs of laryngeal irritation and inflammation. The laryngeal exam identifies edema and erythema, particularly in the posterior region. ${ }^{8}$ These are the main findings used by various investigators for the diagnosis of LPR. ${ }^{8,22}$ Granulomas, contact ulcers, and pseudosulcus (infraglottic edema) are also common findings, and the last has been observed in up to $90 \%$ of cases of LPR. ${ }^{1}$ Laryngoscopy is important because an association seems to exist between cancer and LPR. ${ }^{1,23}$ Reflux has also been shown to be associated with subglottic stenosis, laryngospasm, obstructive sleep apnea, bronchiectasis, and rhinitis or chronic rhinosinusitis. $^{19,23}$ Besides that, according to some investigators, these findings are also seen in healthy subjects, and the type of endoscope can influence the color of erythema. ${ }^{1}$ Furthermore, because the exam depends on the examiner, variations may exist that make the precise diagnosis of LPR highly subjective. ${ }^{24}$

In an attempt to identify the most specific laryngoscopic signs of LPR, Belafsky et al developed the Reflux Finding Score (RFS) based on the findings of fiberoptic laryngoscopy. ${ }^{23}$ This scale evaluates eight items that comprise the most common laryngoscopic findings in patients with LPR: subglottic edema; ventricular obliteration; erythema or hyperemia; vocal fold edema; generalized laryngeal edema; posterior commissure hypertrophy; granuloma or granulation tissue; and excess mucus in the larynx. Each item is scored according to severity, location, and presence or absence, for a total score of 26. Patients presenting a score of 7 or higher are classified as having LPR. In that study, this scale showed excellent reproducibility and, although each item alone was unable to predict the presence or absence of LPR, the total RFS score was highly suggestive of LPR in a patient with a score higher than 7. In addition, this scale is useful to evaluate the efficacy of treatment in patients with LPR (- Table 2 ).

The correlations between laryngeal findings, symptoms, and $\mathrm{pH}$ monitoring have been found to be weak. ${ }^{21,24}$ It has been reported that findings normally associated with LPR may also be found among up to $86 \%$ of healthy controls, as shown in the report by Hicks et al. ${ }^{25}$

Therefore it appears that laryngeal signs are poorly specific for LPR, which can explain why patients initially diagnosed with reflux-related laryngitis often do not respond to appropriate treatment. Regarding LPR, more studies are needed to reveal which signs are truly specific. In one study, vocal lesions were suggested to represent more specific signs for LPR, with $91 \%$ specificity and $88 \%$ response to proton pump inhibitor (PPI) therapy. ${ }^{26}$

It should be emphasized, however, that a thorough medical history and laryngoscopy are important for the proper workup of cases of LPR, precisely because there is no gold standard for diagnosis.

\section{$\mathrm{pH}$ Monitoring}

Reflux events are best demonstrated by multichannel intraluminal impedance pH monitoring. This method is able to detect acid and nonacid or gaseous fluid. ${ }^{20}$ Despite controversy, an LPR event occurs when the $\mathrm{pH}$ of the proximal sensor declines to $<4$ during or immediately after distal acid exposure (near the lower esophageal sphincter) and LPR is confirmed when total acid exposure time (percentage of time during 24-hour monitoring when the sensor detected $\mathrm{pH}$ $<4)$ is $>1 \%^{20}$ Multichannel intraluminal impedance $\mathrm{pH}$ monitoring is useful for the diagnosis of LPR, but the methods tested vary widely and there is no consensus regarding the definition of abnormal $\mathrm{pH}^{27}$ Sataloff et al described a biological variation among individuals. ${ }^{28}$ The diagnostic sensitivity of hypopharyngeal $\mathrm{pH}$ monitoring is only $40 \%{ }^{16}$ Furthermore, $\mathrm{pH}$ monitoring has been shown to be a weak indicator of the severity of signs and symptoms in affected patients. ${ }^{20} \mathrm{~A}$ meta-analysis of 16 studies demonstrated that the number of pharynges with positive reflux 
Table 2 Reflux Finding Score

\begin{tabular}{|c|c|}
\hline \multirow{2}{*}{$\begin{array}{l}\text { Subglottic edema } \\
\text { (pseudosulcus) }\end{array}$} & $0=$ absent \\
\hline & $2=$ present \\
\hline \multirow[t]{3}{*}{ Ventricular obliteration } & $0=$ absent \\
\hline & $2=$ partial \\
\hline & $4=$ complete \\
\hline \multirow[t]{3}{*}{ Erythema/hyperemia } & $0=$ absent \\
\hline & $2=$ only in the arytenoid \\
\hline & $4=$ diffuse \\
\hline \multirow[t]{5}{*}{ Vocal fold edema } & $0=$ absent \\
\hline & $1=$ mild \\
\hline & $2=$ moderate \\
\hline & $3=$ severe \\
\hline & $4=$ polypoid \\
\hline \multirow[t]{5}{*}{ Diffuse laryngeal edema } & $0=$ absent \\
\hline & $1=$ mild \\
\hline & $2=$ moderate \\
\hline & $3=$ severe \\
\hline & $4=$ obstruction \\
\hline \multirow{5}{*}{$\begin{array}{l}\text { Posterior commissure } \\
\text { hypertrophy }\end{array}$} & $0=$ absent \\
\hline & $1=$ mild \\
\hline & $2=$ moderate \\
\hline & $3=$ severe \\
\hline & $4=$ obstruction \\
\hline \multirow[t]{2}{*}{ Granuloma/granulation tissue } & $0=$ absent \\
\hline & $2=$ present \\
\hline \multirow[t]{2}{*}{ Thick endolaryngeal mucus } & $0=$ absent \\
\hline & $2=$ present \\
\hline Total & \\
\hline
\end{tabular}

submitted to 24-hour $\mathrm{pH}$ monitoring differed significantly between patients with LPR and controls. ${ }^{21}$ When used in combination with laryngoscopy and RFS, pH monitoring may contribute to identify patients with a potential response to PPIs. ${ }^{23}$ However, another meta-analysis including 11 studies found no difference in the prevalence of pharyngeal reflux measured by $\mathrm{pH}$ monitoring between patients with LPR and controls, and only a small proportion of the patients with clinically diagnosed reflux laryngitis had pharyngeal reflux. ${ }^{29}$

\section{Empirical Treatment}

In view of the controversial diagnostic criteria for LPR, empirical treatment with PPIs has been used as an alternative diagnostic modality in which a favorable response is defined as diagnostic confirmation. ${ }^{10,27,28}$ The empirical treatment preconized consist of PPI twice a daily for 2 to 3 months. ${ }^{30}$ Most studies consider a favorable response to PPI when the patient reports resolution of symptoms related to $\mathrm{LPR}^{27,31}$

\section{Treatment}

Treatment of LPR consists of dietary changes and changes in habits such as weight loss, quitting smoking, avoiding alcohol, and not eating immediately before bedtime. Dietary restrictions include caffeine, chocolate, gasified beverages, fat, tomato sauce, and red wine. ${ }^{1,19}$ These modifications have been shown to be a significant independent determinant of the response to medicamentous treatment. ${ }^{32}$

At present, the drugs most commonly used for the treatment of LPR are PPIs, which suppress acid production by directly acting on the $\mathrm{H}^{+}-\mathrm{K}^{+}$ATPase of parietal cells. PPIs not only prevent exposure of the upper aerodigestive tract, but also reduce the damage resulting from the enzymatic activity of pepsin, which requires an acid medium for activation. ${ }^{33}$

Clinical evidence indicates that pharmacologic intervention should comprise a minimum of 3 months of treatment with PPIs administered twice a day (40 $\mathrm{mg}$ omeprazole or an equivalent PPI), 30 to 60 minutes before a meal. This period is important because it provides the highest concentration of the drug during the period of stimulation of the proton pump by food consumption. ${ }^{1,19}$

In contrast to GERD, the therapeutic response of patients with LPR to PPIs is variable, ${ }^{22}$ in part because LPR requires more aggressive and prolonged therapy than GERD. ${ }^{26} \mathrm{Al}-$ though most patients show improvement of symptoms within 3 months, the resolution of symptoms and laryngeal findings generally takes 6 months. ${ }^{1,19}$ This variability in response is also due to the failure of studies to standardize inclusion criteria and to stratify groups according to severity, lack of adequate controls, and differences in therapeutic duration and dose.

Studies have tried to establish some standards. Significant failure rates have been reported when a single daily dose of the PPI was used, and most studies suggest adopting a regimen of two daily doses. ${ }^{34,35}$ In the study of Park et al, ${ }^{26}$ a response to the regimen consisting of two daily doses of PPI was observed in $50 \%$ of the patients after 2 months of treatment, whereas only $28 \%$ of the patients receiving a single daily dose responded to treatment. In the single-dose group, $54 \%$ of the patients who had not improved showed improvement of symptoms after an additional 2 months of treatment with two daily doses. After 4 months of treatment with two daily doses, an additional $22 \%$ of the patients had improved, resulting in a response rate of $70 \%$ after 4 months of treatment with two daily doses.

Maximum antireflux treatment consists of the combined administration of a PPI two times per day (before breakfast and dinner) and of an $\mathrm{H} 2$ receptor antagonist before bedtime. ${ }^{4,36}$ Although this regimen results in greater acid suppression than previous medical treatments, the failure rate is still significant (10 to $17 \%$ ). ${ }^{35}$

Studies analyzing the efficacy of PPI therapy in patients with LPR have provided different patterns of response, probably because of variations in the inclusion criteria and the true prevalence of LPR. Most uncontrolled studies suggest a response rate of almost $70 \%$ to PPIs. ${ }^{22}$ In contrast, most controlled trials found no beneficial effect of PPIs when compared with placebo. ${ }^{37}$ Divergent results have been reported in the three 
most recent controlled studies. Fass et al observed no difference in acoustic parameters or voice perception between patients with LPR treated with esomeprazole and the placebo group. ${ }^{38}$ Similarly, Shaheen et al found no difference in chronic cough between patients without burning sensation who used esomeprazole and placebo. ${ }^{39}$ In contrast, in the study of Lam et al involving 24 patients with LPR, rabeprazole was superior to placebo in terms of symptom improvement after 12 weeks of treatment. ${ }^{40}$ In a randomized controlled study including patients with postnasal drip as main symptom, PPI treatment was superior to placebo. ${ }^{41}$

In view of the divergent results and the heterogeneity of patients, many patients may not have LPR, a fact that could explain the high response rate to placebo as observed in other inflammatory diseases or functional gastrointestinal disorders. ${ }^{42}$ However, general consensus suggests initial empirical treatment with PPIs twice a day for 2 to 3 months. ${ }^{30}$

PPIs reduce the volume of acid reflux, but nonacid reflux may still occur. Orally ingested liquid alginate reacts with the acid in the stomach to produce a "raft" that acts as physical barrier to reflux. This is the only nonsurgical treatment that physically prevents acid and nonacid reflux disease. Alginates act rapidly, are long-lasting and inexpensive, and have no known side effects.

\section{Surgery}

Laparoscopic or Nissen fundoplication is a well-established surgical treatment for GERD and produces reliable and reproducible results. ${ }^{43}$ However, its role in the management of LPR is uncertain. A recent study revised an extensive series of patients undergoing fundoplication and found similar improvement in patients with laryngeal findings and typical symptoms of GERD and those with exclusive typical symptoms. In contrast, poor results were obtained for patients with exclusive laryngeal symptoms, but a positive $\mathrm{pH}$ monitoring test for reflux, indicating the possibility that the cause of symptoms is not related to reflux in many of these patients. ${ }^{43}$

It has been suggest that Nissen fundoplication should not be performed in patients resistant to PPIs. ${ }^{27}$ Furthermore, one study showed that only $10 \%$ of patients respond to Nissen fundoplication after failure of PPI therapy, and this response rate did not differ from the group who continued to use PPIs (7\%). ${ }^{44}$ Sataloff et al reported positive results after surgery in symptomatic patients due to nonacid reflux. ${ }^{28}$

\section{Latest Research}

\section{Nonacid Diet and Alkaline Water}

Koufman suggested that pepsin, which is deposited in laryngeal tissue, can be activated by exogenous hydrogen ions derived from any source, including diet. ${ }^{4}$ On the basis of this suggestion, the author conducted a study including patients with LPR who were resistant to PPI treatment. The patients received a restricted nonacid diet for 2 weeks and symptoms improved in $95 \%$ of them. This author also demonstrated that pepsin is irreversibly inactivated in alkaline water at $\mathrm{pH} 8.8$, suggesting therapeutic benefits of alkaline water in patients with reflux disease. ${ }^{6}$

\section{Biomarkers of Reflux}

\section{Inflammatory Cytokines}

Multiple markers have been implicated in inflammation of the esophageal mucosa caused by reflux. GERD alters the expression of interleukin (IL)-6, a cytokine involved in mucosal inflammation induced by reflux. ${ }^{45}$ IL- 6 is known to play a role in acute inflammation and the body's immune response. ${ }^{46}$ Esophageal IL-6 levels increase according to the degree of reflux and decrease after treatment of GERD. IL- 6 seems to be an indicator of mucosal inflammation related to reflux. ${ }^{46}$ Increased expression of IL-8 has also been associated with reflux, especially in esophageal mucosa with Barrett's dysplasia and adenocarcinoma. A decrease in IL-8 levels was observed after antireflux surgery. ${ }^{47}$ An in vitro study demonstrated increased expression of IL- 8 and other inflammatory markers when exposed to pepsin. ${ }^{13}$

\section{Carbonic Anhydrase}

Carbonic anhydrase is a defense component of the mucosa that catalyzes the hydration of carbon dioxide, producing bicarbonate, which neutralizes acid reflux in the extracellular space. In the esophagus, carbonic anhydrase neutralizes acid reflux to almost neutrality. ${ }^{48}$ An increase in the expression of carbonic anhydrase III may be a consequence of epithelial hyperplasia, which is a histopathologic sign of esophagitis. ${ }^{49}$ In patients with LPR, differences in the expression of carbonic anhydrase III were observed between different biopsy sites. ${ }^{49}$ In the presence of LPR and pepsin, the expression of carbonic anhydrase III decreases in the vocal folds, worsening acid-induced damage, and increases in the posterior commissure of the larynx, with the observation of a correlation between the severity of symptoms and levels of this enzyme. ${ }^{11}$

\section{E-Cadherin}

E-cadherin plays an important role in the maintenance of integrity and barrier function of the epithelium. ${ }^{10}$ Pepsin digests the intracellular structures responsible for intercellular cohesion. ${ }^{10}$ E-cadherin levels have been shown to decline in response to $\mathrm{LPR}^{50}$ but it remains unclear whether this decrease is due to reflux components (acid or pepsin) or to the reflux-associated inflammatory response. There is strong evidence that E-cadherin is a tumor suppressor and that the loss of expression of this protein is the first step to tumor invasion. $^{51}$

\section{Mucins}

Mucins are glycoproteins expressed by different types of epithelial cells at sites exposed to oscillations in $\mathrm{pH}$, ion concentration, hydration, and oxygenation. The functions of mucins include protection, lubrication, transport, renewal and differentiation of the epithelium, cell cycle modulation, adhesion, and cell signal transduction. ${ }^{52}$ LPR reduces the secretion of mucins, impairing epithelial protection. Reduced secretion of esophageal mucins has been observed in patients with reflux esophagitis. ${ }^{52}$ 


\section{Discussion}

LPR has become a frequent disease in the otorhinolaryngologist's office. A large number of studies have been published in the medical literature over the last few years, but controversies regarding LPR still exist. ${ }^{49}$ Although nonspecific, the combination of symptoms and characteristic laryngoscopic findings may be more suggestive of LPR. However, investigators highlight the wide variability in the laryngoscopic findings of reflux among examiners. ${ }^{53}$

The reliability of 24-hour $\mathrm{pH}$ monitoring has been questioned, and there is no consensus on the adequate site of the upper probe and interpretation of the results. ${ }^{54}$ At present, the combination of symptoms, laryngoscopic findings, and empirical PPI therapy resulting in symptomatic improvement is used for the diagnosis of LPR. However, if the therapeutic test fails, other diseases should be investigated or it should be considered that reflux components other than acids are the cause of signs and symptoms in the patient. ${ }^{53}$ Studies have demonstrated that not only acid reflux causes damage in LPR, but pepsin and bile acids are also causative agents of inflammation. ${ }^{11,14}$ Particularly pepsin has been increasingly implied in the damage caused by reflux disease, with studies showing its intracellular presence and ability to remain stable in laryngeal tissues, where it can be reactivated by endogenous hydrogen ions (acid reflux) or by exogenous hydrogen ions derived from any source, including diet., 43

Molecular studies have tried to identify biomarkers of reflux, such as ILs, carbonic anhydrase, E-cadherin, and mucins. The data emerging from these studies explain the role of biomarkers not only in mucosal defense mechanisms but also in tumor progression. ${ }^{11}$

Data from controlled studies demonstrate that the outcomes of PPI therapy are comparable to those of placebo treatment. Nevertheless, empirical treatment with PPIs for 2 to 3 months continues to be recommended in the medical literature as a cost-effective and useful therapy for the initial diagnosis of LPR. ${ }^{1}$ In addition to the difficulty in demonstrating the efficacy of PPIs, the diagnosis of LPR remains a challenge in view of the nonspecific signs and symptoms of the condition and the controversial role of $\mathrm{pH}$ monitoring. The result would be an unreal increase in the diagnosis of LPR in patients who do not respond to acid suppression therapy. ${ }^{42}$

Controlled studies have shown low response rates and no significant differences between PPI and placebo treatment, a fact suggesting that patients without typical symptoms of GERD (heartburn or burning sensation) will not benefit from treatment with PPIs. ${ }^{16}$ In contrast to what is seen in GERD, the response to treatment with PPIs varies widely among patients with LPR. Some authors believe that treatment of LPR requires higher doses and longer treatment when compared with GERD. $^{26}$ The recommendation is that empirical therapy should use the full dose of PPIs for a minimum period of 2 to 3 months. ${ }^{1,19}$ In this respect, the results of controlled studies and meta-analyses suggest that the lack of a response to empirical treatment should not lead to an increase of the dose or duration of treatment, but rather to revision of the diagnosis. ${ }^{27}$ Recommendations for PPI treatment in patients with a suspicion of LPR are based on the results of uncon- trolled studies, and the high response rates to placebo treatment suggest a much more complex and multifactorial pathophysiology of LPR than simple acid reflux. ${ }^{10}$ Further studies are needed to characterize subgroups of patients with symptoms of LPR who would benefit from treatment with PPIs.

\section{Conclusion}

LPR is a disease commonly diagnosed in otorhinolaryngologic practice in the presence of a set of nonspecific laryngeal signs and symptoms. The cause of laryngeal damage is uncertain but is likely to comprise a combination of acid and reflux components, particularly pepsin. Pepsin is associated with nonacid or weakly acid reflux. This enzyme remains stable in laryngeal tissues and is reactivated by subsequent reflux or by dietary acids.

There is no specific test for LPR. Laryngoscopy and $\mathrm{pH}$ monitoring have failed as reliable tests for the diagnosis of this condition. Empirical therapy with PPIs has been widely accepted as a diagnostic test and for the treatment of LPR. Other treatment options include lifestyle and dietary changes (quitting smoking and drinking, weight loss, avoiding caffeine, etc.).

Molecular studies have been conducted in an attempt to identify biomarkers of reflux, such as ILs, carbonic anhydrase, E-cadherin, and mucins. However, further investigation is needed to establish a definitive diagnostic test for LPR and to determine the mechanism underlying mucosal damage, which would contribute to the development of new treatments and the understanding of the physiopathology of LPR.

\section{References}

1 Ford CN. Evaluation and management of laryngopharyngeal reflux. JAMA 2005;294:1534-1540

2 El-Serag HB. Time trends of gastroesophageal reflux disease: a systematic review. Clin Gastroenterol Hepatol 2007;5:17-26

3 Altman KW, Stephens RM, Lyttle CS, Weiss KB. Changing impact of gastroesophageal reflux in medical and otolaryngology practice. Laryngoscope 2005;115:1145-1153

4 Koufman JA. Low-acid diet for recalcitrant laryngopharyngeal reflux: therapeutic benefits and their implications. Ann Otol Rhinol Laryngol 2011;120:281-287

5 Pohl H, Welch HG. The role of overdiagnosis and reclassification in the marked increase of esophageal adenocarcinoma incidence. J Natl Cancer Inst 2005;97:142-146

6 Koufman JA, Johnston N. Potential benefits of pH 8.8 alkaline drinking water as an adjunct in the treatment of reflux disease. Ann Otol Rhinol Laryngol 2012;121:431-434

7 Fraser AG. Review article: gastro-oesophageal reflux and laryngeal symptoms. Aliment Pharmacol Ther 1994;8:265-272

8 Koufman JA. The otolaryngologic manifestations of gastroesophageal reflux disease (GERD): a clinical investigation of 225 patients using ambulatory 24-hour $\mathrm{pH}$ monitoring and an experimental investigation of the role of acid and pepsin in the development of laryngeal injury. Laryngoscope 1991; 101(4 Pt 2, Suppl 53):1-78

9 Belafsky PC, Postma GN, Koufman JA. Validity and reliability of the reflux symptom index (RSI). J Voice 2002;16:274-277 
10 Wood JM, Hussey DJ, Woods CM, Watson DI, Carney AS. Biomarkers and laryngopharyngeal reflux. J Laryngol Otol 2011;125:1218-1224

11 Johnston N, Knight J, Dettmar PW, Lively MO, Koufman J. Pepsin and carbonic anhydrase isoenzyme III as diagnostic markers for laryngopharyngeal reflux disease. Laryngoscope 2004;114:2129-2134

12 Johnston N, Yan JC, Hoekzema CR, et al. Pepsin promotes proliferation of laryngeal and pharyngeal epithelial cells. Laryngoscope 2012;122:1317-1325

13 Samuels TL, Johnston N. Pepsin as a causal agent of inflammation during nonacidic reflux. Otolaryngol Head Neck Surg 2009;141: 559-563

14 Johnston N, Wells CW, Blumin JH, Toohill RJ, Merati AL. Receptormediated uptake of pepsin by laryngeal epithelial cells. Ann Otol Rhinol Laryngol 2007;116:934-938

15 Johnston N, Dettmar PW, Lively MO, et al. Effect of pepsin on laryngeal stress protein (Sep70, Sep53, and Hsp70) response: role in laryngopharyngeal reflux disease. Ann Otol Rhinol Laryngol 2006;115:47-58

16 Vaezi MF. We should learn from important negative results. Laryngoscope 2009;116:1718

17 Sasaki CT, Marotta J, Hundal J, Chow J, Eisen RN. Bile-induced laryngitis: is there a basis in evidence? Ann Otol Rhinol Laryngol 2005;114:192-197

18 Lillemoe KD, Johnson LF, Harmon JW. Role of the components of the gastroduodenal contents in experimental acid esophagitis. Surgery 1982;92:276-284

19 Bove MJ, Rosen C. Diagnosis and management of laryngopharyngeal reflux disease. Curr Opin Otolaryngol Head Neck Surg 2006;14:116-123

20 Noordzij JP, Khidr A, Desper E, Meek RB, Reibel JF, Levine PA. Correlation of $\mathrm{pH}$ probe-measured laryngopharyngeal reflux with symptoms and signs of reflux laryngitis. Laryngoscope 2002;112: 2192-2195

21 Merati AL, Lim HJ, Ulualp SO, Toohill RJ. Meta-analysis of upper probe measurements in normal subjects and patients with laryngopharyngeal reflux. Ann Otol Rhinol Laryngol 2005;114: 177-182

22 Vaezi MF, Hicks DM, Abelson TI, Richter JE. Laryngeal signs and symptoms and gastroesophageal reflux disease (GERD): a critical assessment of cause and effect association. Clin Gastroenterol Hepatol 2003;1:333-344

23 Belafsky PC, Postma GN, Koufman JA. The validity and reliability of the reflux finding score (RFS). Laryngoscope 2001;111:1313-1317

24 Branski RC, Bhattacharyya N, Shapiro J. The reliability of the assessment of endoscopic laryngeal findings associated with laryngopharyngeal reflux disease. Laryngoscope 2002;112:10191024

25 Hicks DM, Ours TM, Abelson TI, Vaezi MF, Richter JE. The prevalence of hypopharynx findings associated with gastroesophageal reflux in normal volunteers. J Voice 2002;16:564-579

26 Park W, Hicks DM, Khandwala F, et al. Laryngopharyngeal reflux: prospective cohort study evaluating optimal dose of proton-pump inhibitor therapy and pretherapy predictors of response. Laryngoscope 2005; 115:1230-1238

27 Abou-Ismail A, Vaezi MF. Evaluation of patients with suspected laryngopharyngeal reflux: a practical approach. Curr Gastroenterol Rep 2011;13:213-218

28 Sataloff RT, Hawkshaw MJ, Gupta R. Laryngopharyngeal reflux and voice disorders: an overview on disease mechanisms, treatments, and research advances. Discov Med 2010;10:213-224

29 Joniau S, Bradshaw A, Esterman A, Carney AS. Reflux and laryngitis: a systematic review. Otolaryngol Head Neck Surg 2007;136: 686-692

30 Kahrilas PJ, Shaheen NJ, Vaezi MF; American Gastroenterological Association Institute; Clinical Practice and Quality Management Committee. American Gastroenterological Association Institute technical review on the management of gastroesophageal reflux disease. Gastroenterology 2008;135:1392-1413, e1-e5
31 Reimer C, Bytzer P. Management of laryngopharyngeal reflux with proton pump inhibitors. Ther Clin Risk Manag 2008;4:225-233

32 Steward DL, Wilson KM, Kelly DH, et al. Proton pump inhibitor therapy for chronic laryngo-pharyngitis: a randomized placebocontrol trial. Otolaryngol Head Neck Surg 2004;131:342-350

33 Dobhan R, Castell DO. Normal and abnormal proximal esophageal acid exposure: results of ambulatory dual-probe $\mathrm{pH}$ monitoring. Am J Gastroenterol 1993;88:25-29

34 Leite LP, Johnston BT, Just RJ, Castell DO. Persistent acid secretion during omeprazole therapy: a study of gastric acid profiles in patients demonstrating failure of omeprazole therapy. Am J Gastroenterol 1996;91:1527-1531

35 Amin MR, Postma GN, Johnson P, Digges N, Koufman JA. Proton pump inhibitor resistance in the treatment of laryngopharyngeal reflux. Otolaryngol Head Neck Surg 2001;125:374-378

36 Koufman JA, Aviv JE, Casiano RR, Shaw GY. Laryngopharyngeal reflux: position statement of the committee on speech, voice, and swallowing disorders of the American Academy of Otolaryngology-Head and Neck Surgery. Otolaryngol Head Neck Surg 2002; 127:32-35

37 Qadeer MA, Phillips CO, Lopez AR, et al. Proton pump inhibitor therapy for suspected GERD-related chronic laryngitis: a metaanalysis of randomized controlled trials. Am J Gastroenterol 2006;101:2646-2654

38 Fass R, Noelck N, Willis MR, et al. The effect of esomeprazole $20 \mathrm{mg}$ twice daily on acoustic and perception parameters of the voice in laryngopharyngeal reflux. Neurogastroenterol Motil 2010;22:134141, e44-e45

39 Shaheen NJ, Crockett SD, Bright SD, et al. Randomised clinical trial: high-dose acid suppression for chronic cough-a double-blind, placebo-controlled study. Aliment Pharmacol Ther 2011;33: 225-234

40 Lam PK, Ng ML, Cheung TK, et al. Rabeprazole is effective in treating laryngopharyngeal reflux in a randomized placebo-controlled trial. Clin Gastroenterol Hepatol 2010;8:770-776

41 Vaezi MF, Hagaman DD, Slaughter JC, et al. Proton pump inhibitor therapy improves symptoms in postnasal drainage. Gastroenterology 2010;139:1887-1893, e1, quiz e11

42 Patel SM, Stason WB, Legedza A, et al. The placebo effect in irritable bowel syndrome trials: a meta-analysis. Neurogastroenterol Motil 2005;17:332-340

43 Ratnasingam D, Irvine T, Thompson SK, Watson DI. Laparoscopic antireflux surgery in patients with throat symptoms: a word of caution. World J Surg 2011;35:342-348

44 Swoger J, Ponsky J, Hicks DM, et al. Surgical fundoplication in laryngopharyngeal reflux unresponsive to aggressive acid suppression: a controlled study. Clin Gastroenterol Hepatol 2006;4:433-441

45 van Roon AH, Mayne GC, Wijnhoven BP, et al. Impact of gastroesophageal reflux on mucin mRNA expression in the esophageal mucosa. J Gastrointest Surg 2008;12:1331-1340

46 Hirano T. Interleukin 6 in autoimmune and inflammatory diseases: a personal memoir. Proc Jpn Acad, Ser B, Phys Biol Sci 2010;86: 717-730

47 Oh DS, DeMeester SR, Vallbohmer D, et al. Reduction of interleukin 8 gene expression in reflux esophagitis and Barrett's esophagus with antireflux surgery. Arch Surg 2007;142:554-559, discussion 559-560

48 Tobey NA, Powell DW, Schreiner VJ, Orlando RC. Serosal bicarbonate protects against acid injury to rabbit esophagus. Gastroenterology 1989;96:1466-1477

49 Axford SE, Sharp N, Ross PE, et al. Cell biology of laryngeal epithelial defenses in health and disease: preliminary studies. Ann Otol Rhinol Laryngol 2001;110:1099-1108

50 Reichel O, Mayr D, Durst F, Berghaus A. E-cadherin but not $\beta$-catenin expression is decreased in laryngeal biopsies from patients with laryngopharyngeal reflux. Eur Arch Otorhinolaryngol 2008; 265:937-942 
51 Kurtz KA, Hoffman HT, Zimmerman MB, Robinson RA. Decreased Ecadherin but not beta-catenin expression is associated with vascular invasion and decreased survival in head and neck squamous carcinomas. Otolaryngol Head Neck Surg 2006;134:142-146

52 Samuels TL, Handler E, Syring ML, et al. Mucin gene expression in human laryngeal epithelia: effect of laryngopharyngeal reflux. Ann Otol Rhinol Laryngol 2008;117:688-695
53 Mahieu HF. Review article: the laryngological manifestations of reflux disease; why the scepticism? Aliment Pharmacol Ther 2007;26(Suppl 2):17-24

54 Sato K, Umeno H, Chitose S, Nakashima T. Tetra-probe, 24-hour pH monitoring for laryngopharyngeal reflux: a technique for simultaneous study of hypopharynx, oesophagus and stomach. J Laryngol Otol 2009;123(Suppl 31):117-122 